\title{
$11^{\mathrm{TH}}$ CONFERENCE ON COMPETITION AND OWNERSHIP IN LAND PASSENGER TRANSPORT
}

Delft University of Technology (The Netherlands)

20-25 September 2009

\section{ARE WE DOING IT WRONG OR DO WE EXPECT TOO MUCH? FORCES THAT PUSH AUTHORITIES TO BECOME PUBLIC TRANSPORT DESIGNERS}

\author{
David Eerdmans \\ inno- $V$ consultancy \\ Amsterdam \\ de@inno-v.nl \\ Sebastiaan van Kooij \\ inno-V consultancy \\ Amsterdam \\ svk@inno-v.nl
}

Didier van de Velde

Delft University of Technology

Faculty of Technology, Policy and Management

d.m.vandevelde@tudelft.nl

Hans Westerink

inno- $V$ consultancy

Amsterdam

hw@inno-V.nl

\section{ABSTRACT}

Based on experiences with tendering and organizing meetings to exchange lessons between parties involved in tendering, the authors search for reasons for disappointment of authorities in operators' efforts to develop PT in favour of their travellers. There are three main causes: (1) there is freedom, but the contract is bad, (2) there is freedom, there is a good contract, but there is no market and (3) there is freedom, but the operator is not able to use it. The authors also mention some keys to prevent disappointment. 


\section{INTRODUCTION}

The authors of this paper have advised several passenger transport authorities in the Netherlands in the context of Public Transport (PT) competitive tendering procedures. They have also organized meetings for authorities, operators and advisors to exchange experiences on tendering PT in the Netherlands. This paper attempts to present some of these experiences focusing on the theme of this paper, being the reasons that push authorities to have an increasing influence of the design of the public transport services they contract out.

\section{SHIFT IN THE RESPONSIBILITIES ON THE TACTICAL LEVEL}

The Dutch public transport regime was revolutionized by the introduction of a competitive tendering (further abbreviated to 'CT') regime in 2001. Since then, the Dutch public transport legislation (Passenger Transport Act 2000, further abbreviated to 'PTA2000') requires passenger transport authorities to establish public transport policy goals, to define concession areas and, gradually, to organize CT procedures to award exclusive concessions for up to 8 years in the bus sector and 15 years in the railway sector. One of the ideas behind the Passenger Transport Act 2000 was to give freedom to the operators on the tactical level. They were considered to be best suited to design the product in such a way that it meets the needs of the passengers. However, there are major differences between authorities in the amount of freedom on the tactical level given to the operators (van de Velde et al., 2008). Some authorities tend to give operators as much freedom as possible within the established transport policy context (Stadsregio Amsterdam, Zuid-Holland, Limburg). Others try to control the output of a tender and operation of public transport by designing the PT-product (on the tactical level) themselves (OV-Bureau Groningen-Drenthe, Noord-Brabant). Obviously, as authorities are forced to tender according to the PTA2000, authorities cannot design the PT-product at the operational level. This remains a task for the operators, being the party dealing directly with the passengers.

These differences in approach that were described in earlier papers (van de Velde and Pruijmboom, 2005; van de Velde et al., 2008; Veeneman et al., 2007) continue to evolve. Even after 9 years of tendering we can continue to see shifts in different directions: some authorities who used to give freedom to operators were disappointed and now want to control more aspects on the tactical level, while others that did not do so now give more freedom.

We will first sum up possible reasons for disappointment. Secondly, we will present a few of the solutions that authorities currently develop and we will try to ascertain whether this might lead to a reduction in future causes of disappointment and to an improvement in the relation between authorities and operators. This will provide a short analysis of the degree to which this solution could contribute to reversing the trend. Finally we will draw some conclusions and perspectives.

\section{POSSIBLE REASONS FOR DISAPPOINTMENT}

We will focus on the former of the two evolutions stated above (some authorities who used to give freedom to operators were disappointed and now want to control more 
aspects on the tactical level) as this movement is contrary to the general idea behind the PTA2000. As we will see, several authorities tried giving freedom to operators but were disappointed with the results. Their reaction was to become public transport designers themselves. In this paper we try to find out which reasons lie behind this disappointment. Authorities perceive the problem as the operator not trying hard enough to develop the PT product and to attract new customers. Is this the real reason? And is taking over these responsibilities by authorities the right solution for the problem?

Our advisory experience leads us to the following categorisation of possible reasons for disappointment by authorities. We make a distinction between three main categories of reasons:

- Contractual reasons: the contract provided too little freedom and/or effective incentives for the operator;

- Market reasons: the development potential of the concession was too small for development in practice;

- Organizational reasons: cultural differences between authorities and operators, and/or incompetence by the operator.

Each of these will be presented below.

\section{Contracts}

\section{No freedom due to a large amount of requirements}

One of the possible reasons for disappointment is that the actual freedom given to the operator is smaller than what the authority aimed for.

Some authorities want to give freedom to the operator, however, the contractual demands are so high that the remaining amount of freedom is actually very small. This has to do with a search for certainty, especially by those actors involved in a tendering procedure who do not feel the way a contract can provide quality by leaving uncertainties uncertain.

In the end, Regional politicians, part of the authority, are politically responsible for the result of a tender. The easiest way to be certain of the result is to increase the amount of demands. This is often stimulated by local politicians, feeling the same responsibility and anxious of loosing a bus line or a bus trip. Thus the social aims of an authority become overwhelmingly important in contrast to quality and accessibility aims. Politicians are not always as much interested in a contract that benefits the role of operators and authorities and the result for travelers as they are in realizing or defending a concrete result. Civil servants willing and preparing to optimize their contract for the tender as well as the operation during contract period are thus restricted by 'their' politicians and thus the potential effect of their set of incentives. This is subscribed by several authorities in a project called Beter Bestek (literally "Better Terms of Reference"). By this project, initiated by the Knowledge Centre for Transport (KpVV), experiences of authorities, operators and consultants on $\mathrm{CT}$ have been exchanged for three years now. 
In addition, spatial contraints such as the availability of roads further restricts the freedom by the operator. In many cases, the combination of current passenger demand and available roads leaves very little freedom in designing the public transport network.

In our experience when tendering the Leeuwarden urban network in 2006, the general idea was to give freedom to the operator during the tender process to redesign the network. Operators participating in the tender could win a significant amount of awarding points by doing so. However, the resulting network was almost identical to the network before tendering. There was some disappointment about this, but was this really a bad result? Looking back at it, there were not many other possible networks that could serve the current passenger demands in an effective way.

Also, the city region of Rotterdam has this experience in tendering the Voorne Putten area for the first time. Because there is only one road axis with separate bus lanes, all operators in tender offered a comparable network, although the winning operator offered one important new connection to Rotterdam. However, this has not been a success since buses had substantial delays caused by traffic jams on the highways the bus line needed. The number of travelers decreased and eventually the operator and authority decided to stop this connection.

Perhaps it is not realistic to expect that in a short period of time an operator can design a completely new network that is much better than the current network that has gradually been developed and re-adjusted over decades.

\section{Bad contract: Not the right incentives}

Another possible reason for disappointment about lack of action by transport operators is that contracts may have freedom for the operator, but lack effective incentives.

For example: cost coverage in the Netherlands is $40 \%$, so even when the revenue risk is allocated to the operator, $60 \%$ of its income will be (more or less) fixed. This means that alternative incentives are needed to stimulate the operator towards (re)developing the transit network and product with the (potential) customer in mind. This is especially true regarding developments where additional rolling stock is needed: new lines as well as more service during peak hours.

However, authorities are often not very likely to include significant incentives in the contract. In one case that we experienced the authority intended to include some major incentives related to passenger growth, passenger satisfaction and operational quality. However, the desired level of incentives was at the same time being regarded as 'politically impossible', as politicians and the public would regard this as 'presents towards the operator'. Allowing major companies to make profits from public funds was seen as undesirable and out-of-the-question, even when doing so would improve the quality of public transport.

Also, in interviews within 'Beter Bestek', parties involved in tendering notice that they are in search of the right incentives, incentives that fit their contracts context. In about 8 years of tendering PT in the Netherlands most authorities have tendered all their concessions once or more. Thus they have experienced the way their first sketch of incentives did function. 
One experience heard often is that operators did not do more than they offered to win the tender. Even with a bonus incentive on, most often, quality aspects measured by customer satisfaction, operators did not invest more in satisfying their customers. Operators claim that the range of the bonus is too small to compensate investments needed: it is not profitable. They also claim that the main focus is to reduce financial risks. Some of these risks are caused by maluses on the same quality aspects. The main problem for operators is that they can hardly influence customer satisfaction in the degree needed for a bonus, because the realisable change is only a small fraction on a scale of 10 while customers tend to give a seven when service is OK. Apparently service is $\mathrm{OK}$ and hard to improve in a degree that it makes a great difference for travellers.

Lastly, the province of Noord-Brabant is an example known in the Netherlands by its attempt to design the PT product as much as possible after a sequence of disappointments in their relation with the operator and later on with several attempts to tender. After these attempts, the tender succeeded eventually and a research committee was appointed by the Provincial Council "analyse the facts with the 2005 and the 2006 CT and to prevent similar mistakes from happening again" (van de Velde et al., 2008). One of the observations was that "the authority provided too detailed a programme of requirements for the services to produce and attempted, in legal and procedural terms, to work too much exactly according to legal requirements. Sticking strictly to these aims, the Province eliminated any space it had for adaptation during the procedure." A lack of trust of the authority in the operator stimulated the authority to a formal stance, with legal aspects dominating the process as well as ignoring signals from operators before and during the tender. Van de Velde et al. (2008) conclude that much of this illustrates the lack of attention paid to the 'relationship factor' (is the nature of the contact between the parties such that adequate business can be realised?)

\section{No market}

\section{There is no market in the first place}

Authorities expect operators to develop their product during their contract. This is also the idea behind the PTA2000. However, in practice not every area has so much potential for growth of demand and change of the PT product. Especially on the countryside the main goal of public transport is to provide a minimum service for inhabitants to be able to travel to social and economic activity locations. The number of inhabitants, the concentration of people living in this area, the degree of sprawl of households as well as activity locations, makes it hard to provide a profitable PT service: not enough people are travelling and they do so in too many directions.

The importance on this social aim of public transport makes it difficult for an authority to leave space for development on the one hand and to decrease uncertainties about upkeeping of the 'social bus lines' on the other hand. In practice these contract do not leave much space for development. However, e.g. the tender document of South-East Fryslân, which is a very low dense rural area, did leave some space for the operator to look for clusters of connections to market as a more profitable connecting line. 
A realistic market forecast is needed to have an effective set of incentives during tender and concession period. The province of Overijssel is now tendering Mid-Overijssel. Overijssel also was disappointed in the performance of the current operator: "The concession holder turned out to be insufficiently focused on customer and provincial interests, impeding our attempts as a province to effectively and efficiently implement our public transport policy." (Dijkstra and Verheijdt, 2009). Mid-Overijssel is mostly a rural area, with only two cities (Deventer and Zwolle). In the current invitation to tender this contract Overijssel did acknowledge the fact that the scope of possible change of the PT product is poor. This is why Overijssel demands operators to offer the current network and schedule. Overijssel focuses on building a relationship to develop together, using each others strengths. More about this further on.

\section{No market: counterproductive policies by authorities}

A focus on road infrastructure, and a sprawling spatial planning which is more geared towards automotive mobility reduce the potential market for public transport. Spatial developments that are facilitated or influenced by regional governments develop in a way counterproductive to effective Public Transport. The most familiar example of this effect did occur at so called VINEX-areas. VINEX is the name of a Strategic Spatial Plan which encompasses several new large locations to build houses. These locations were rural areas or industrial zones (even an air strip) and are situated in, but mostly just outside of a city. Although the PT-accessibility of these areas has been one of the key arrangements for facilitating accessibility and mobility, Public Transport started operations only after a significant part of housing production was already built and used (RIGO Research en Advies and OTB Delft, 2007).

Moreover, the bus and tramlines concerned are mostly only connected with the city centre it is adjacent to, while a large part of the mobility of this new housing area is not going to the city centre. People travel to other cities and other parts of the city that are more close to the new housing area. However, they do not travel by PT, because connections are lacking or very poor. Inhabitants are forced to use their cars and face traffic jams on the highway close to the housing area. 'Good' examples of these ereas are Carnisselande (next to Rotterdam, but next to Europoort Harbour and Dordrecht) en Leidsche Rijn (next to Utrecht, but close to the highways to Amsterdam, The Hague and Rotterdam). Another car minded developments are large-scale business areas located at highway view locations.

It is distressing that regional governments invest a lot in PT while lacking incentives to increase the number of inhabitants around PT-corridors. To be profitable and to offer a high quality standard (high frequencies fast and slow connections), these corridors would need a large number of passengers (Eerdmans et al., 2009).

Further more, provinces, but mainly municipalities are responsible for the maintenance of roads. In favor of traffic safety these organizations improve their roads by slowing down traffic. This reduces the speed of public transport. Municipalities do not feel responsible for the accessibility aims of public transport. Mostly social aims are taken into count. It is difficult for a province to coordinate and to link the interests of PT operators with road managers. One of the keys in this need for coordination lies in the lack of focus in mobility policy; what is more important is mostly not so obvious. This 
might be one of the reasons that the part car mobility takes in mobility as a whole is still roughly the same as 10 years ago.

\section{Organisations}

\section{Cultural differences between authorities and operators}

Operators are perceived as being 'evil', while in face the authority does not always understand the way an operator acts. In sessions and interviews organized for KpVV (project "Better Contract") authorities tell that most of them are disappointed in the attitude of an operator. E.g. often is that operators seek to find not-in-service trips that can be transferred to scheduled trips, which leads to extra possibilities for people to travel, however in time and place totally not interesting to use for customers.

While authorities try to realize policy aims concerning accessibility, mobility, social connectivity and environment improvements, operators are stimulated to compete with each other on these to win tenders and operators need to minimize risks while having limited 'financial space' as a buffer. A clear distinction between these to parties is described in a summarised way by Van de Velde (2008) where autorities and operators are described as coming respectively from Venus and from Mars. Their focus can also be sketched as such:

\begin{tabular}{|l|l|}
\hline Venus & Mars \\
\hline Politicians & Operators, commercial parties \\
\hline 'Peace' & Chances \\
\hline No fuss & Risks \\
\hline Travelers / Customer & Money \\
\hline
\end{tabular}

One of the keys lies in the authority's manpower. Some authorities lack enough tendering experience and evaluation, because of staff exchanges. Several authorities tender only once in a couple of years. Thus tendering PT is not always one of the core activities. This relates to the quality of a contract as mentioned in the first part of this paper. Also, authorities do often not know what requirements cost. This way a decision to for instance using PT for social mobility is not based on a cost benefit analysis, but on a search for political certainty.

Moreover, in case of the focus of this paper, is that an authority has to have the manpower and competences to fulfill its role. For instance, the province of NoordBrabant decided to tender a contract by which the authority develops on the tactical level. In practice, after one year of exploitation, Noord-Brabant is still dealing with the problem not having enough experienced manpower to do so (van de Velde et al., 2008).

\section{Operator fails}

It is not only the authority not understanding how an operator acts. Operators do fail in practice, although partly caused by authorities. For example one of the first tendered contracts: BRU Northwest. This concession has a mix of connecting lines using the A2 
highway for 20 kilometres, city-regional lines and social service lines. The number of travellers increased in the years before tendering, but after tendering decreased. This did not stop during the contract period.

There are two explanations for this situation. One, because it was one of the first tenders in the Netherlands, competition was large and experience at the operators was little. The winning bid for this contract was financially tight. This was already stated by Van de Velde and Pruijmboom (2005). An authority can influence the degree in which an operator can be a low cost operator. Second, the operator was not able to take the freedom it has during the concession, because of its organizational form: all activities for handling a contract took place in the concession area. On the one hand this seems positive because as a company it is possible to keep feeling with things happening in the concession area. On the other hand it turned out to be negative, because there were too few experienced employees to deal with daily practice as well as coping with the results of their offer and changes within and problems with the area itself.

The same happened in the concession called Veluwe, part of the province of Gelderland. Operator of this concession BBA Connex did offer concrete and realistic proposals for development of the area, but due to lack of attention of both the operator as well as the authority, nothing has been realised, although there should be something to win.

\section{ALTERNATIVE SOLUTIONS}

Most of the experiences presented here corroborate the conclusions of a paper that was also presented at the last Thredbo conference and in which the authors state that (van de Velde et al., 2008):

- Authorities often have very high expectations about how actively operators will develop services.

- This mismatch is caused by:

○ "political influence constraints on service supply"

- "contractual incentives often proven to be to weak"

- "budget cuts during the contract"

- lack of trust - "Longva and Osland (2007) state that tendering has to rely on thin-trust relations"

o "the incentives given by the bid valuation model were not always clear nor properly reflecting the Terms of References and transport policy aims", and;

0 authorities seem to have too little knowledge on the cost consequences of many of their choices, obligations and wishes in the context of CT.

The authors give a few lessons "that authorities could use to improve the set up of their CT procedures, contracts and relation with operators":

- "Aligning aims between authority and operator: Stanley et al. (2007) underlines the importance of accepting the legitimacy of each other's goals as authority and operator. One should add that in the contractual design this can be supported by aligning those goals through incentives." 
- "Using control or cooperation to set-up the relationship": therefore aligned incentives "can form a basis for cooperation"

- "The awarding model needs a strong penalty for underperformance in order to balance the tendency to overbid in this awarding model."

- "Qualitative judgements provide an attractive element to diminish possibilities of strategic bidding."

- During concession periode "incentives should focus the operator more on the authority's needs during the concession."

In practice some authorities try new ways to their relation with operators, some in line with the lessons as stated above. For these authorities, for instance the 'OV Bureau Groningen Drenthe' (already functioning and to be improved) and the province of Overijssel (now tendering several of their concessions) the disappointment and the perceived urge to develop services has lead to new forms of cooperation.

The OV Bureau Groningen Drenthe is a cooperation of two authorities: the provinces of Groningen and Drenthe. This organization exists for several years now. They make their choices on the tactical level while the operators can almost only make choices on the operational level. An operator can come forth with ideas however. This is an example of aligned incentives and having manpower organized effectively.

Overijssel for instance 'forces' operators to participate in so-called development teams. In this way the operators have to think about new initiatives, marketing and promotion champagnes, and so on. On top of that, the authority is also part of this development team. This way aims between authority and operator can be aligned during the development process. The operator and authority thus can use each others strengths to compensate weaknesses. Often daily operational issues are delegated to other teams, so the focus can be aimed at projects for improvement. This focus is part of the tender document and incentives in tender procedure as well as incentives for the contract period tend to be aligned.

Although this forced cooperation could lead to mutual understanding, it remains to be seen whether this form of partnership anchored in a tender document will lead to large leaps. It is crucial that the operator has enough (financial) incentive to actively cooperate in this partnership. In Overijssel, the development team has access to a budget on which it can make decisions autonomously. If that were not the case, the decisiveness of the development team would be lower. On top of that, if the operator is responsible for passenger income and operational costs, he could easily block new developments if they are too expensive or if the financial compensation is too low.

\section{CONCLUSIONS AND PERSPECTIVES}

We started this paper by stating that authorities perceive the problem as the operator not trying hard enough to develop the PT product and to attract new customers. We questioned whether this is the real reason and whether taking over these responsibilities by authorities is the right solution for the problem.

In short, we stated that there are mainly three reasons for disappointment: 
- There is freedom, but the contract is bad. We have seen cultural differences, intention for freedom for the operator which in practice is minimized by for instance striphing for certainty by politicians, and real freedom with to less incentives;

- There is freedom, there is a good contract, but there is no market. The number of inhabitants to convince to use public transport is much smaller than an authority is aware of, regional governments do not stimulate supporting spatial planning and road managers

- There is freedom, but the operator is not able to use it. Although this paper, and earlier published papers, focus on the role and competence of the authorities, the operator is also not always able to use its freedom, mainly because of lack of manpower.

Taking over responsibilities by authorities might work as is seen in the case of the OV Bureau Groningen Drenthe, although it is not in line with expectations by the PTA2000. The proposed development team of Overijssel makes it possible to align aims between authority and operator during the development process. However, an authority using this idea of cooperation has to question whether the contract incentives will be in line with the authority's aims with their relation with the operator to prevent disappointment.

This paper is based on experiences with tendering and learning from feedback and interaction between authorities, operators and consultants. It is nice to observe that these parties feel the need to learn further from each other. The analysis of our experiences is stated in this and earlier papers. This paper might be helpful in the analysis to be conducted by all parties to thoroughly improve the authorities' contracts moving towards less (unexpected) disappointments.

\section{REFERENCES}

Dijkstra, W. and P. Verheijdt (2009), "Relationship after tender: teamwork with incentives", 11th International conference on competition and ownership in land passenger transport, Delft, 2025 September 2009.

Eerdmans, D.A., S.C.E. van Kooij and D.M. van de Velde (2009), "Denken, doen en laten: Onderzoek, overheidsingrijpen en ondernemerschap voor een beter OV", Colloquium Vervoersplanologisch Speurwerk, Antwerp, 19-20 November 2009.

Longva, F. and O. Osland (2007), "Organising Trust. On the Institutional Underpinning and Erosion of Trust is Different Organisational Forrms in Public Transport", In: Competition and Ownership in Land Passenger Transport, Selected papers from the 9th International Conference (Thredbo 9), Lisbon, September 2005 (Eds.: Macario, R., J. Viegas and D.A. Hensher), 489-500, Elsevier Science, Amsterdam.

RIGO Research en Advies and OTB Delft (2007), "Evaluatie Verstedelijking VINEX 1995 tot 2005, eindrapport", Ministerie VROM/Directoraat-Generaal Ruimte \& NIB / Cluster Beleidsevaluatie \& Uitvoeringscoördinatie, Delft / Den Haag.

Stanley, J., J. Betts and S. Lucas (2007), "Tactical Level Partnerships; a Context of Trust for Successful Operation", In: Competition and Ownership in Land Passenger Transport, Selected papers from the 9th International Conference (Thredbo 9), Lisbon, September 2005 (Eds.: Macario, R., J. Viegas and D.A. Hensher), 189-212 Elsevier Science, Amsterdam.

Van de Velde, D.M. (2008), "Hoe laten we het OV beter functioneren?", Economisch-Statistische Berichten, 4549, 768.

van de Velde, D.M. and E.A.M. Pruijmboom (2005), "First experiences with tendering at the tactical level (service design) in Dutch public transport", In: Competition and Ownership in Land Passenger Transport (Ed.: Hensher, D.A.), 213-237, Elsevier, Amsterdam.

van de Velde, D.M., W.W. Veeneman and L. Lutje Schipholt (2008), "Competitive tendering in The Netherlands: Central planning vs. functional specifications", Transportation Research Part A, 42, 1152-1162. 
Veeneman, W.W., D.M. Van de Velde and L. Lutje Schipholt (2007), "Competitive tendering in the Netherlands: 6 lessons from 6 years of tendering", European Transport Conference 2007, Noordwijkerhout, 17-19 October 2007. 